\title{
Structure Analysis of Deep Water Spar Platform
}

\author{
Wenjia HU ${ }^{\text {a, } 1}$ and Shisheng WANG ${ }^{\text {a }}$ \\ ${ }^{\text {a } C N O O C ~ R e s e a r c h ~ I n s t i t u t e, ~ B e i j i n g, ~ C h i n a ~}$
}

\begin{abstract}
In order to study calculation technology of global structure strength for the deep water typical Spar platform its global structural strength analysis is completed. The dynamic-part and a low frequency-part loads are considered in this analysis. First, according to the 100 -year return storm design wave parameters are obtained through search. wave loads with design wave parameters are calculated, and are applied to the structural model built. The stresses of global structure are gotten by finite element structural analysis. Then, low frequency-part loads which include wind, current and mooring forces also are applied to the structural model. The stresses produced by low frequency-part loads are gotten by finite element structural analysis. Finally the stresses produced by dynamic-part and a low frequency-part loads are combined to form total stresses of structure of Spar, and evaluation of structural strength of Spar is made in term of the rule. Analysis method for the structural strength of the deepwater typical Spar platform can be used as reference for relative technical people.
\end{abstract}

Keywords. Deep water typical spar platform, structural model, finite element, stress, strength analysis

\section{Introduction}

The deepwater SPAR platform is the supporting facility for deepwater oil and gas field development. In order to ensure the structural safety of the Spar platform, a structural strength analysis of the Spar platform was carried out. The analysis of SPAR global structure involves the calculation and analysis of wave load, the transfer of wave load to the structure model, the establishment of the global structure model, and the evaluation of the global structure strength [1]. In order to obtain more accurate global stress distribution trend and stress level of the structure, the modeling of SPAR platform and the calculation and transmission of wave load are studied in depth. On this basis, the global structure evaluation is carried out, and some conclusions are obtained, which are of certain reference significance to the related researchers. .

\section{Spar Principal Dimensions}

The SPAR platform consists of three main components: the upper facility module, the platform body (including hard tank, trusses and soft tank), and the mooring system. The global dimensions of the Spar platform studied are shown in table 1.

\footnotetext{
${ }^{1}$ Wenjia Hu, CNOOC Research Institute, Beijing, China; E-mail: huwj19@cnooc.com.cn.
} 
According to the total scale of the platform and the structural design specification, the structural size of the hard tank, soft tank and truss of the SPAR is determined [2].

Table 1. Spar principal dimensions.

\begin{tabular}{|c|c|c|c|}
\hline drilling deck $(\mathrm{m} \times \mathrm{m})$ & $64.084 \times 50.293$ & Middeck $(\mathrm{m} \times \mathrm{m})$ & $64.084 \times 50.293$ \\
\hline Under the deck $(\mathrm{m} \times \mathrm{m})$ & $64.084 \times 50.293$ & $\begin{array}{l}\text { Lower deck to top of the hard } \\
\operatorname{tank}(\mathrm{m})\end{array}$ & 7.62 \\
\hline Under the deck to & 8.53 & Middeck to & 7.3 \\
\hline $\begin{array}{l}\text { Intermediate deck distance } \\
\text { (m) }\end{array}$ & & Drilling deck distance $(\mathrm{m})$ & \\
\hline Hard tank diameter $(\mathrm{m})$ & 39.00 & Height of soft tank (m) & 6.401 \\
\hline Hard tank length (m) & 72.542 & soft tank size $(m)$ & $39 \times 39$ \\
\hline Center well size (m) & $15.393 \times 15.393$ & Buoyancy tank height (m) & 39 \\
\hline Truss length (m) & 90.221 & Buoyancy tank size $(\mathrm{m})$ & $39 \times \times 11.804$ \\
\hline Truss Leg (m) & 27.587 & draft $(\mathrm{m}) /$ displacement (Tons) & $153.924 / 85784.3$ \\
\hline $\begin{array}{l}\text { Variable amount of ballast } \\
\text { (Tons) }\end{array}$ & 8478.4 & Fixed ballast weight (Tons) & 11221.4 \\
\hline Number of heave plates & 2 & heave plates size $(\mathrm{m})$ & $39 \times 39$ \\
\hline
\end{tabular}

\section{Structural Analysis Method}

The Spar platform is a slender offshore structure, which bears more complex environmental loads. Not only the wave-frequency load, but also the low-frequency load caused by the wave, as well as the effect of wind and flow, should be consider

The wave frequency load is to calculate the bending moment, transverse shear force and axial tension pressure according to the specifications and load conditions, and then the design wave parameters of the typical wave conditions are determined. Then, the finite element analysis model of the global structure of the Spar platform is established, and the wet surface hydrodynamic pressure and inertial acceleration of each typical wave condition are applied to the global finite element model. The SESAM/SESTRA program is used for quasi-static structural finite element analysis, and the structural analysis of the wave frequency part is completed. The analysis of the low frequency part requires the aid of the overall coupling analysis software DeepC to calculate the mooring force and the inclination angle of the platform at the maximum tilt state. The same overall structure model of the Spar platform is used to apply various low-frequency loads and hydrostatic pressure, and then the SESAM/SESTRA program is used for static finite element analysis. Finally, SESAM's post-processing program PREPOST is used to superimpose the wave-frequency and low-frequency finite element structure analysis results to obtain the total calculation result. After obtaining the total calculation results, the strength of the main structure of the Spar platform is evaluated according to the stress criteria specified in the ABS specification.

\section{Structural Stress Analysis}

\subsection{Wave Frequency Load Acting on the Spar Platform}

The wave load in all loads borne by spar is the control load designed for the deep-water floating production platform. The magnitude of the wave load acting on the platform 
depends on the wave direction, period and wave height. The wave load is composed of wave frequency components and low frequency components [3], and the wave frequency components can be determined by the design wave method. The so-called design wave method is to search for the wave period and wave direction according to the specified working conditions, and finally determine a regular wave that can produce the maximum load on the structure, and then apply this regular wave to the structure for platform structure analysis.

According to the ABS specification, the design wave analysis of the Spar platform is carried out. The 9 sections are selected along the axial direction, and the numbering sequence is from the top of Spar to the baseline, section 1 to section 9. The extreme sea environmental conditions (environmental conditions that occur once in a hundred years) is adopted for sea conditions of analyze. The design wave search under extreme sea environmental conditions is carried out according to specifications. According to the calculation results, the maximum value of the maximum shear force and the horizontal bending moment does not appear under the environmental conditions with the maximum wave height, but appears near the wave period of 10 seconds to 11 seconds. However, the axial force increases as the wave height increases. The final design wave parameter results are shown in table 2.

Table 2. Calculation results of design wave parameters.

\begin{tabular}{lllllll}
\hline & Section & Load & \multicolumn{4}{l}{ Design wave parameters } \\
\cline { 4 - 6 } & & & $\begin{array}{l}\text { Wave direction } \\
\text { (degee) }\end{array}$ & $\begin{array}{l}\text { Amplitude } \\
(\mathrm{m})\end{array}$ & $\begin{array}{l}\text { Wave height } \\
(\mathrm{m})\end{array}$ & Period $(\mathrm{s})$ \\
$\begin{array}{l}\text { Horizontal } \\
\text { shear (N) }\end{array}$ & section8 & $5.18 \times 107$ & 0 & 11.67 & 23.34 & 10.00 \\
$\begin{array}{l}\text { Bending } \\
\text { moment(N-m) }\end{array}$ & section7 & $1.99 \times 109$ & 0 & 11.83 & 23.65 & 11.00 \\
$\begin{array}{l}\text { Axial force } \\
(\mathbf{N})\end{array}$ & section2 & $1.08 \times 108$ & 90 & 9.35 & 18.70 & 24.00 \\
\hline
\end{tabular}

\subsection{Low Wave Frequency Load Acting on The Spar Platform}

Because the Spar platform is a slender structure, it is tilted at an angle under the action of wind, current and second-order low-frequency load. The wave force changes after the tilt angle of the floating body is not large, but the overall bending and shearing of the Spar are affected. The dangerous position of Spar is not the hard tank and the soft tank, but the connection position between the two and the truss. Therefore, under the action of wind, waves, and currents, when Spar is inclined to the maximum angle, Spar receives the greatest force. The global structural stress calculation is carried out according to this working condition.

Low-frequency loads include: wind force, flow force, mooring force. To estimate the wind area according to the global layout of the upper module, and the magnitude of the wind power is calculated according to the API RP2A-WSD specification. The magnitude of the wind force is calculated based on the wind speed that occurs once in a hundred years. Calculation of the flow force is based on the flow profile given in table 3. 
Table 3. The velocities of deep ocean currents in different water depth in the 100 year return period.

\begin{tabular}{lll}
\hline Water depth $(\mathrm{m})$ & Unit & Velocities of ocean currents \\
\hline $0.1 \mathrm{~h}$ & $\mathrm{~cm} / \mathrm{s}$ & 184 \\
$0.3 \mathrm{~h}$ & $\mathrm{~cm} / \mathrm{s}$ & 132 \\
$0.5 \mathrm{~h}$ & $\mathrm{~cm} / \mathrm{s}$ & 93 \\
$0.7 \mathrm{~h}$ & $\mathrm{~cm} / \mathrm{s}$ & 71 \\
$0.9 \mathrm{~h}$ & $\mathrm{~cm} / \mathrm{s}$ & 54 \\
H: water depth $(1500 \mathrm{~m})$ & & \\
\hline
\end{tabular}

The formula for calculating the flow force is:

$$
F_{C}=\frac{1}{2} C_{D} \rho A V_{C}^{2}
$$

In the formula $C_{D}$ is drag force coefficient; $\rho$ is sea water density; $A$ is the projected area of the structure in the vertical flow direction; $V_{C}$ is flow velocity..

The calculation formula for the outer surface of the hard cabin of the Spar platform (DNV-RP-F205) is:

$$
C_{D}=C_{D O}+2 C_{\text {Strake }} h / D
$$

Where $C_{D O}$ is the drag force coefficient of the outer surface of the hard tank without the spiral strip; $C_{\text {strake }}$ is the drag coefficient of the spiral strip; $h$ is the height of the spiral strip; D is the diameter of the hard tank. The Calculated $C_{D}$ is equal to 1.1 1.5.

The maximum inclination angle of Spar given by the calculation of global performance is 10.63 degrees.

The low-frequency load, wind and flow load acting on the Spar platform are obtained by calculation.In the stress analysis, these loads are respectively applied to the Spar platform structure model for finite element analysis. Other loads that need to be considered in the analysis include: hydrostatic pressure; riser and mooring loads; deadweight loads; operating loads; inertial loads.

\subsection{Global Structure Model of Spar Platform}

Spar platform consists of upper module, hard tank soft tank and truss structure. The hard and soft tank adopt the form of plate frame structure, that is, ring T-section beams (Ring Girders) and longitudinal stiffeners (Stiffeners) are added to the plate surface. In the modeling, all plates and shells are simulated by plate elements; Ring Girders in the hard tank and the webs of the longitudinal reinforced frame and transverse deck in the soft tank are simulated by plate elements, and the panels are simulated by beam elements.; The longitudinal stiffeners (Stiffeners) are all simulated by beam elements, and all equipment in the upper block is simulated by mass elements. In addition, the quality of the water enclosed in the well in the Spar also is simulated in the global model. In the global model, no specific structural details are simulated, such as the brackets and stiffeners of secondary components. The global structure model is shown in figure 1 


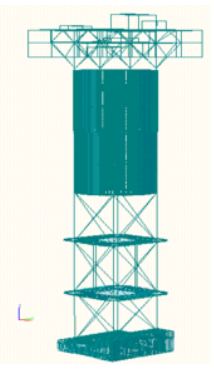

(1) Global Structure.

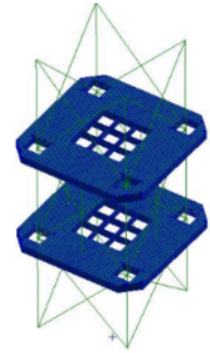

(2) Truss.

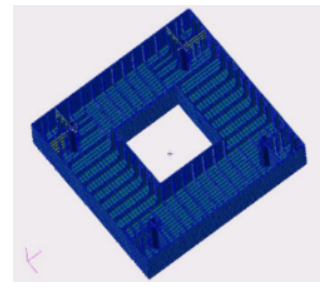

(3) Soft Tank Structure.

Figure 1. Spar global structure model.

\subsection{Boundary Conditions and External Load Application}

The structural analysis of Spar is divided into wave-frequency structural analysis and low-frequency structural analysis according to the type of load it bears. In the case of wave frequency, the inertial force and wave force in the $\mathrm{x}, \mathrm{y}$, and $\mathrm{z}$ directions, gravity and buoyancy are balanced. At low frequencies, wind, current and mooring forces, gravity and buoyancy are also balanced, theoretically, no boundary conditions are required. However, in the structural calculation, the six rigid body degrees of freedom of the Spar platform need to be constrained to limit the rigid body displacement. Under various load conditions in the global structure analysis, all six restraint reaction forces are required to be zero. The boundary conditions on the model are imposed on two mooring points and a point on the top of the hard tank.

\subsection{Wave-frequency Structural Analysis}

Wave frequency structure analysis only considers the influence of wave generated hydrodynamic pressure on the structure. The hydrodynamic pressure can be directly transferred and applied to the structural model through the WADAM module of the SESAM program. In addition, the inertial acceleration of the platform with six degrees of freedom is applied to the finite element structure model to ensure balance with the hydrodynamic load. Due to the simplification of the structural finite element model, the weight of the model is different from the actual platform weight. This can be achieved by adjusting the material density to balance the structural weight and buoyancy. The Morison force acting on the truss can also be directly transferred to the corresponding structural member using the WADAM module. After the hydrodynamic load is transferred to the Spar structure model, the finite element analysis module Sestra of the SESAM program can be used for structural finite element analysis. The stress analysis result of Spar structure under wave frequency load is obtained through structural finite element calculation.

\subsection{Low-frequency Structural Analysis}

The low-frequency structural analysis of the Spar platform is to apply wind force, flow force and mooring force, as well as hydrostatic pressure and buoyancy force on the global structure model of Spar platform, and All external forces exerted on the global 
structure of the Spar platform constitute a balanced force system. After applying a lowfrequency load to the Spar structure model, The finite element analysis module Sestra of the SESAM program can also be used for structural finite element analysis.

\subsection{Superposition of Wave Frequency and Low Frequency Calculation Results}

After the wave frequency and low frequency finite element calculations are completed, according to the principle of linear superposition, the wave frequency and low frequency finite element calculation results can be added together to obtain the total calculation result. The superposition of the calculation results is done by using the postprocessing module Prepost of the SESAM program. The post-synthesis analysis result file can also use the post-processing program Xtract to view the global structural stress analysis results of the Spar platform.

\section{Structural Stress Analysis}

\subsection{Allowable Stress}

According to ABS MODU [4] and CCS [5] specifications, the allowable stress is calculated by the following formula:

$$
F_{a}=F_{y} / F \cdot S
$$

Among them: $F_{y}$ is the yield stress; F.S. is the safety factor. Table 4 shows the allowable stress and stress safety factor under different load conditions.

Table 4. Allowable stress and safety factor.

\begin{tabular}{lccc}
\hline Load & F.S. & $\begin{array}{c}\text { Allowable stress (Mpa) } \\
\left(F_{y}=355 \mathrm{MPa}\right)\end{array}$ & $\begin{array}{c}\text { Allowable stress (Mpa) } \\
\left(F_{y}=550 \mathrm{MPa}\right)\end{array}$ \\
\hline Static & 1.43 & 248 & 385 \\
Combined load & 1.11 & 320 & 495 \\
\hline
\end{tabular}

Note: The combined load is the combination of static load and wave load.

\subsection{Stress Distribution and Calculation Results}

\subsubsection{Load Combination Condition 1: Wave direction $0^{\circ}$, Period 10s}

Through structural finite element analysis, the stress distribution obtained is shown in figure 2 . When the wave direction is $0^{\circ}$ and the period is $10 \mathrm{~s}$, the maximum equivalent stress of the structure is $128.351 \mathrm{Mpa}$. The stress distribution diagram shows that the places with the greatest stress are the four inner corners of the square hole in the second deck of the upper hard tank, while the stress levels in other parts are not high. The stress levels in the middle of the Spar hard tank, the connection between the hard tank and the truss, and the connection between the hard tank and the upper module are higher than other parts. 


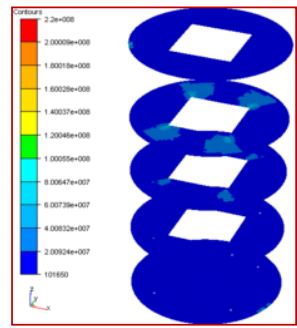

(a) Deck Stress distribution.

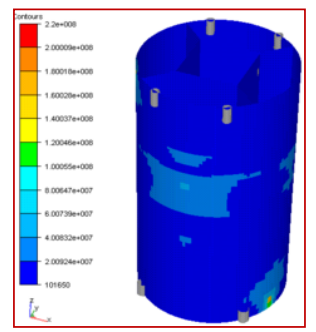

(b) Hard tank stress distribution.

Figure 2. Hard tank and Deck Stress distribution (Wave direction $0^{\circ}$, period $10 \mathrm{~s}$ ).

\subsubsection{Load Combination Condition 2: Wave Direction $0^{\circ}$, Period $11 \mathrm{~s}$}

Through structural finite element analysis, the stress distribution obtained is shown in figure 3 . When the wave direction is $0^{\circ}$ and the period is $11 \mathrm{~s}$, the maximum equivalent stress of the structure is $407.664 \mathrm{Mpa}$. The stress distribution diagram shows that the places with the greatest stress are near the connection point between the hard tank and the upper module and the connection part between the hard tank and truss, while the stress levels in other parts are not high. The stress level in the middle of the Spar hard tank is slightly higher than other parts. The stress level at the connection between the soft tank and truss and the connection between the floating tank and the ballast tank is higher than other parts.

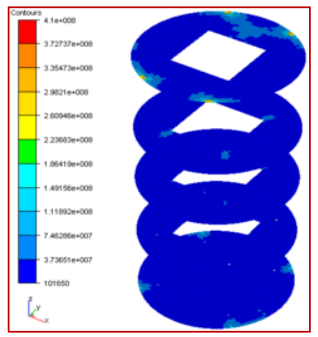

(a) Deck Stress distribution.

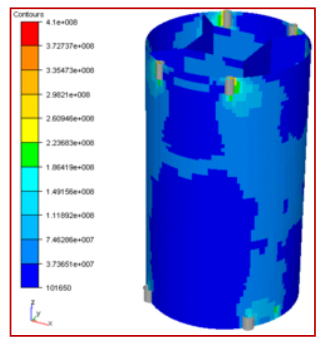

(b) Hard tank stress distribution.

Figure 3. Hard tank and Deck Stress distribution (Wave direction $0^{\circ}$, period $11 \mathrm{~s}$ ).

\subsubsection{Load Combination Condition 3: Wave Direction $90^{\circ}$, period $24 \mathrm{~s}$}

Through structural finite element analysis, the stress distribution obtained is shown in figure 4. When the wave direction is $90^{\circ}$ and the period is $24 \mathrm{~s}$, the maximum equivalent stress of the structure is $415.035 \mathrm{Mpa}$. The stress distribution diagram shows that the places with the greatest stress are near the connection point between the hard tank and the upper module, the connection between the hard tank and the Truss is slightly lower, while the stress level in other parts is not high. The stress level in the middle part of the Spar hard tank is higher than other parts. The global stress level of the soft cabin is not high. The stress at the connection between the soft tank and truss, and the connection between the soft tank and the floating tank shell is higher than other parts. The stress level at some corners of girders in the soft tank is relatively high. 


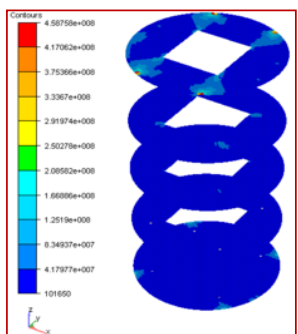

(a) Deck Stress distribution.

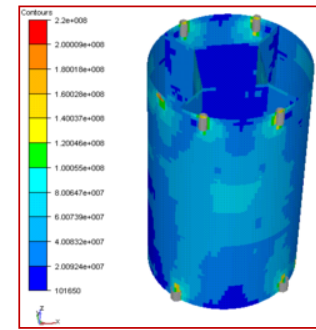

(b) Hard tank stress distribution.

Figure 4. Hard tank and Deck Stress distribution (Wave direction $90^{\circ}$, period $24 \mathrm{~s}$ ).

According to the structural finite element analysis results of the Spar platform, under the three combined conditions, the maximum equivalent stress of the structure mainly appears at the upper module connection point on the top of the hard tank, and the connection between the hard tank and the truss, while the stress levels in other parts are not high.

\section{Conclusion}

The global structural stress analysis of the Spar platform also considers the influence of wave frequency and low frequency loads on structural stress. Firstly, the design wave method is used to predict the wave load of the target platform in various typical wave conditions, the wave load is applied to the global structure model, and the finite element analysis technology is used to structurally analyze the stress of the main structure of the platform. Secondly, the low-frequency load is applied to the global structure model, and the finite element structure calculation is carried out. Finally, the two are superimposed to obtain the overall structure analysis result. The calculation results show that the stress distribution of the main structure of the platform is relatively uniform, the structural design is relatively reasonable, and only high stress occurs at the connection part between the hard tank and the upper module. These parts need to be improved by local reinforcement, or use higher-strength steel. According to the specifications, the main structure of the platform can basically meet the strength requirements.

\section{References}

[1] Wang SS, Xie B, Xie WH. Research on calculation technology of global strength of deepwater semisubmersible drilling platform. Oil Field Equipment. 2009 May; 38(5): 1-4.

[2] Wang SS, Li XZ, Xie B. Research on global design method and global performance of deepwater truss spar platform. In: Yan A,Xiang X editors. The 15th China Ocean (Shore) Engineering Academic Discussion Conference Proceedings; 2011 Aug 3-6; Taiyuan, SHANXI Province: BeiJing: Ocean Press; 94-99.

[3] Zhang HY, Zhao WB, Tang YG. Calculation of wave load on the main body of the deep-water Spar platform. Journal of Ocean University of China. 2008 March; 38(3): 508-512.

[4] American Bureau of Shipping. ABS rules for building and classing mobile offshore drilling units: Part 3 - Hull construction \& equipment, Chapter 2, Section 1. 2012. Jan; 55-60

[5] China Classification Society. Classification rules for offshore mobile platforms t, Chapter 3, Section 4. 2014 Sept.: 10-11. 